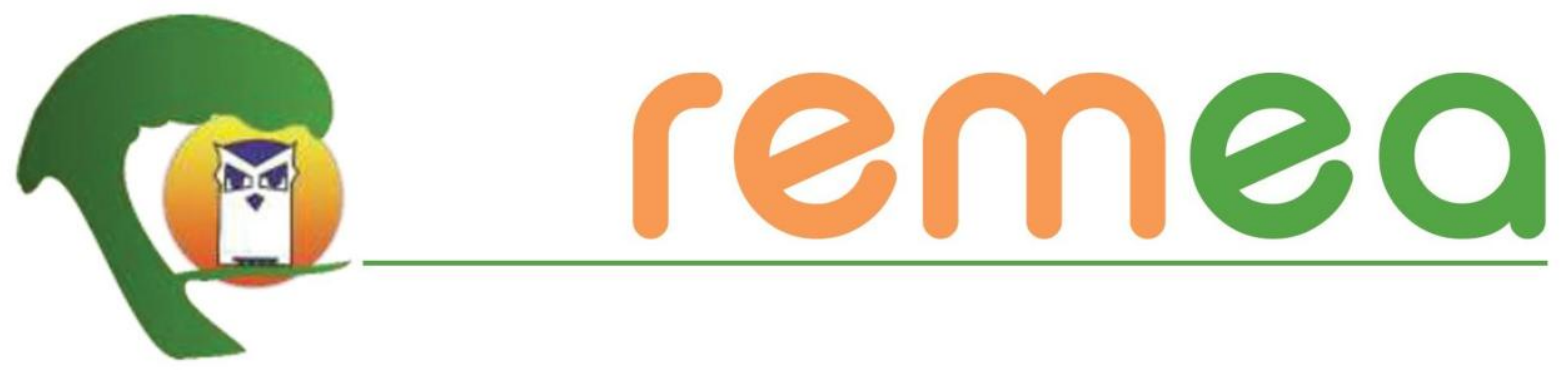

\title{
A produção da pesquisa em Educação Ambiental no Nordeste e Pesquisa Dialógica
}

\author{
João Batista de Albuquerque Figueiredo ${ }^{1}$ \\ Universidade Federal do Ceará - UFC \\ ORCID: http://orcid.org/0000-0002-6199-8324
}

Resumo: O presente artigo apresenta uma pesquisa quali-quantitativa que objetiva anunciar o estado da arte da Pesquisa em Educação Ambiental (EA), no âmbito dos Programas de Pós-Graduação, do Nordeste Brasileiro, até 2018. Utilizamos como referencial teórico-metodológico a Pesquisa Dialógica associada à Bricolagem, enquanto método e técnica de pesquisa. Investigamos todos os grupos de pesquisa que se diziam trabalhar com EA e dissertações e Teses que traziam como palavra-chave essa temática. Dialogamos com artigos, com vistas à interagir e aprofundar reflexões. Como resultado, constatamos que existe uma certa volaticidade no que se refere a explicitar as opções teóricas, ainda que exista forte tendência da pesquisa em EA se identificar com as abordagens ditas críticas de EA. Porém, muitas ainda se configuram concretamente como propostas fenomenológicas, compreensivistas, sem impacto efetivo nas transformações sociais desejadas.

Palavras-Chave: Pesquisa em Educação Ambiental, Pesquisa Dialógica, Bricolagem.

\section{La producción de Investigación en Educación Ambiental en el Nordeste e Investigación Dialógica}

Resumen: Este artículo presenta una investigación cualitativo-cuantitativa que tiene como objetivo dar a conocer el estado del arte de la Investigación en Educación Ambiental (EA), en el ámbito de los Programas de Posgrado, en el Noreste de Brasil, hasta 2018. Utilizamos la Investigación Dialógica como marco teórico y metodológico asociado al Bricolage, como método y técnica de investigación. Investigamos todos los grupos de investigación que afirmaron trabajar con EE y disertaciones y tesis que utilizaron este tema como palabra clave. Dialogamos con artículos, con miras a interactuar y profundizar reflexiones. Como resultado, encontramos que existe una cierta volatilidad en términos de explicar las opciones teóricas, aunque existe una fuerte tendencia a que la investigación en EA se identifique con los llamados enfoques críticos de EA. Sin embargo, muchas aún se configuran concretamente como propuestas fenomenológicas, comprensivista, sin impacto efectivo en las transformaciones sociales deseadas.

Palabras clave: Investigación en Educación Ambiental, Investigación Dialógica, Bricolaje.

The production of Research in Environmental Education in the Northeast

${ }^{1}$ Doutor em Educação Ambiental - Ecologia e Recursos Naturais pela Universidade Federal de São Carlos (2003). É professor adjunto da Faculdade de Educação e Professor-Pesquisador do Programa de PósGraduação em Educação da Universidade Federal do Ceará. E-mail: mailto:joaofigueiredo@hotmail.com 
Abstract: This article presents a qualitative-quantitative research that aims to announce the state of the art of Environmental Education Research (EE), within the scope of graduate programs in northeastern Brazil, until 2018. We used as theoretical-methodological reference the Dialogical Research associated with bricolage, as a method and technique of research. We investigated all the research groups that were said to work with EE and dissertations and theses that brought this theme as a keyword. We dialogue with articles, with a view to interacting and deepening reflections. As a result, we found that there is a certain volatility in terms of explaining theoretical options, even though there is a strong tendency for research in EE to identify with the socalled critical approaches to EE. However, many are still concretely configured as phenomenological, comprehensive proposals, with no effective impact on the desired social transformations.

Keywords: Research in Environmental Education, Dialogic Research, Bricolage.

Iniciamos este trabalho com cordiais saudações a todxs ${ }^{2}$ que dialogam conosco nesse momento difícil da história do nosso Brasil. Jamais imaginaria, nos piores pesadelos viver esse momento e suas possíveis consequências para quem idealiza um mundo melhor, no qual seja possível amar, ser feliz, compartilhar solidariamente a vida e as riquezas da vida.

Temos trabalhado com o referencial de Paulo Freire (1983; 1992; 1996; 2000; 2001), bem como com a (De)Colonialidade, da qual destacamos aqui algumas autorias, tais como: Quijano (1991; 2005), Walsh (2008; 2009), Coronil (2005), Mignolo (2005), Lander (2005), Figueiredo (2010). Também temos dialogado com a ideia da Interculturalidade Crítica de Walsh (2008; 2009) e de Fleuri (1998), ao aproximar esse debate com os estudos da Educação Popular. Temos também leituras de Boaventura de Sousa Santos (2008; 2010; 2010b), que traz para esse diálogo a questão das epistemologias do sul.

Trabalhamos individual e coletivamente, com uma metodologia denominada de Pesquisa Dialógica, fundamentada nos contributos de Paulo Freire, particularmente em seus livros de base: a Pedagogia do Oprimido, Educação como prática da liberdade, Comunicação ou extensão, Pedagogia da Esperança, Pedagogia da Autonomia. Esses contributos fundantes se associaram aos aportes decorrentes da pesquisa engajada.

A Pesquisa Dialógica segue as reflexões de Paulo Freire aplicadas ao campo da pesquisa, em particular no âmbito da investigação Temática. Ela compreende que pesquisar

\footnotetext{
${ }^{2}$ Com este símbolo trazemos uma opção política de explicitar que utilizamos simultaneamente os gêneros feminino e masculino. Ao invés de usar os substantivos e complementos nominais no masculino, gramaticalmente correto, utilizamos este símbolo para levantar a questão política e cultural do sexismo de nossa linguagem.
} 
implica em uma busca de desvelar a realidade, com foco em propósito pré-definido. Esse, por sua vez, permite a definição de situação-limite e fomentar de tema gerador daí decorrente. Destacamos ainda que é bem comum encontrarmos essa pretensão identificada com uma questão pessoal e autoformadora.

Em outras palavras, uma pesquisa dialógica, comumente, apresenta proposta que emerge de uma pergunta de partida que, no caso da dialogicidade, geralmente eclode de uma situação social concreta que se requer transformar. Nesse movimento de transformação social, temos também uma formação pessoal e coletiva. Portanto, é um procedimento alquímico, para além de transmutador. (I)

Depois de definirmos coletivamente, numa negociAção, os propósitos da pesquisa dialógica, passamos ao passo seguinte que é planejar a caminhada rumo ao desvelar de nossos propósitos e transformar a realidade, numa pretensão do inédito-viável, do sonho possível, da u-topia - o lugar que ainda será. O próprio conceito de caminho para ir mais além, sentido etimológico de "método", aqui encontra eco. (II)

Nesse ato de definir o prumo e o modo de caminhar, relembramos que as interlocuções se dão de modo horizontal e compartilhado, em que cada autor(a) social reconhece sua relevância e essencialidade na tessitura dos procedimentos e ações de desvelar, de mapear as chamadas situações-limite, que por sua vez trazem implícito o tema gerador, ou temas geradores, tanto quanto os vocabulários comuns a se estabelecer, com a finalidade de viabilizar o diálogo. Nessa direção, vamos mapeando os interesses e a teia epistêmica que favorece a percepção e o conjunto representacional decorrente de nossa investigação. Com esse embasamento, vamos destrinchando o campo de observação e análise, coletando aportes, localizando indícios e pistas das múltiplas dimensões, como também através das múltiplas linguagens. Destacamos que o mundo é tão diverso e repleto de polifonias, polissemias, multissemiose (multiplicidade de semioses ou linguagens). São inúmeras as leituras distintas possíveis. As interpretações mais diversas e diferentes se manifestam no cotidiano impregnando de mil sentidos e significados o que se apresenta diante de nossas percepções, sem falar das que optamos por focar, destacar ou distinguir. 
A disjunção e diferença marcam fortemente a economia cultural contemporânea. Ainda que não se saiba até quando e por quanto tempo viveremos retrocessos, nestes aspectos, diante de recrudescimentos impostos em decorrência da eclosão da extrema direita, mundo afora. Mesmo assim, resistindo a esta realidade multiforme e policrômica que se impõe aos nossos perceberes, constatamos uma diversidade de narrativas, possíveis deslocamentos conceituais, visuais, diante das diferenças entre pontos de vista, perspectiva de olhar, posição e localização da leitura, subjetividades e objetividades. Assim, o foco é que vai definir nossa leitura, sem desconsiderar outras leituras viáveis. Podemos, inclusive, dialogar, com outras leituras, sentidos, significados... (III)

Dessa maneira, chegamos ao tema que será apresentado por meio de uma codificação que permite decodificações múltiplas, incitadoras da dialogicidade interpretativa que apresenta e representa e abre alternativas de constatações de nossas descobertas transitórias a serem compartilhadas. (IV).

Esse passo cria as condições para os passos seguintes, que seriam: a partilha dos resultados (V); a possível transformação social/grupal/individual (VI) e a avaliação do processo (VII).

Apresentada a proposta de pesquisa dialógica, ainda que de maneira aligeirada, vamos agora alinhavá-la com o propósito desse trabalho. Salientamos que este artigo inédito decorreu de uma pesquisa inspirada por uma demanda do FORPRED Nordeste com o intuito de verificar a produção do conhecimento dos grupos de pesquisa em educação do Nordeste, ligados ao campo de estudos da Educação Ambiental (EA). A ideia era o mapeamento de grupos de pesquisa vinculados aos PPGEs do Nordeste, considerando a área da EA; análise de trajetórias de grupos de pesquisa do Nordeste, relacionados aos temas/questões da área de conhecimento do GT, com destaque para temáticas centrais (ementa), linhas de pesquisa, parcerias e/ou articulações intra e interinstitucionais/nacionais e internacionais; pesquisas realizadas e em andamento; principais metodologias utilizadas; contribuição para a área e a emergência e/ou consolidação de programas de pós-graduação stricto sensu. A ideia seria evidenciar quem produz, o que se produz e como se produz nesses contextos de elaboração do conhecimento, considerando aspectos qualitativos e quantitativos. 
Naturalmente, desde já expressamos escusas diante da nossa incapacidade de atender essa ampla gama de pretensões. Desse modo, fizemos recortes e definimos que trataríamos de mapear, no cenário dos Programas de Pós-graduação em Educação - PPGEs, se haviam linhas de pesquisa ou eixos de pesquisa associadas à temática: Educação Ambiental, em seguida localizar dissertações e teses que tratassem explicitamente desse tema, trazendo em seu título a palavra-chave "Educação Ambiental" - EA. Nesse caso, verificaríamos isso, por meio de seus resumos, opções metodológicas e referenciais teóricos. Também, pretendíamos identificar os grupos de pesquisa associados a 'Educação Ambiental'. Trabalhamos, então com o período do advento das pesquisas registradas em EA até o ano de 2018, tempo pré-pandêmico.

A escolha pelo mapeamento via PPGEs, decorreu em virtude da nossa impossibilidade de efetivar essa investigação por meio dos grupos de pesquisa, já que se apresentava inviável o acesso aos grupos, com a intencionalidade de nos apropriarmos das produções por esse meio. Ainda tentamos acesso através do Projeto EArte - Estado da Arte da Pesquisa em Educação Ambiental (http://www.earte.net/teses/), porém, por esse caminho ficamos sem conseguir associar dissertação e tese com o grupo de pesquisa.

Mesmo diante desses fatos, que inviabilizaram a realização do que pretendíamos, acredito que nossa escolha, em si, oferece um bom contributo para o estado da arte da EA no Nordeste. Esperamos poder efetivamente abrir porteiras de novas e mais profundas investigações, nesse campo tão vasto, abrangente e aberto aos futuros desbravamentos.

Seguindo nessa direção, embora com limites óbvios por se tratar de uma pesquisa que porta uma dimensão bibliográfica/documental, como por implicar em natural redução do impacto dialogal do processo, vamos conectar os passos do caminho com a estrutura da pesquisa dialógica, tal como informamos anteriormente. Assim sendo, ao apresentar a ementa e o recorte que fizemos, estamos a ilustrar o passo I da pesquisa.

O passo II definiu como seria possível efetivar nossa pretensão. Para tanto, dialogamos com alguns /algumas interlocutorxs de nosso grupo de pesquisa e definimos um modelo operacional interessante. Tratamos de ter nesse processo uma investigação bibliográfica/'documental', que utilizou a observação indireta, em que o pesquisador não 
submete o objeto de estudo pelos próprios sentidos, mas capta informações a respeito de objetos já pesquisados pela observação de terceiros. Mas que, na sequência utilizou esse material para analisar e sintetizar algumas derivações, ilações e reflexões dialogicamente no que trata das opções metodológicas e referenciais teóricos mais comuns e frequentes, escolhidos pelxs pesquisadorxs e orientadorxs envolvidos com a temática da EA nordestina.

Nesse caminhar, a coleta de dados foi realizada no mês de outubro e novembro de 2018, por meio do Google acadêmico (https://scholar.google.com.br/), do Catálogo de teses e dissertações da Coordenação de Aperfeiçoamento de Pessoal de Nível Superior - CAPES (http://catalogodeteses.capes.gov.br/catalogo-teses/\#!/), banco de teses de cada PPGE, a partir das palavras-chave: "Educação ambiental". Assim, buscamos, de forma conjunta, as produções informadas pelos PPGEs, tendo essa referência. Ainda utilizamos, como critério de inclusão, estar com resumo disponível na data da consulta.

Reafirmando e detalhando, identificamos os PPGEs filiados à ANPEd, ForpredNordeste. Em seguida, procuramos verificar se haviam linhas de pesquisa ou dissertações e teses nas quais aparecesse a categoria 'Educação Ambiental' no título. Posteriormente fomos verificar, através dos resumos, características dessas produções. Naturalmente, reconhecemos as limitações dessa escolha, porém, seria inviável realizar de outra maneira essa tarefa, em decorrência das contingencias temporais que impuseram escolhas e seleções. Isso foi bastante agravado por conta do momento confuso que estávamos vivendo, numa conjuntura, resultante de uma grave escolha eleitoral, prenunciada por empreitadas políticas que mobilizou muitxs de nós, em um longo e difícil movimento... e que resultou numa escolha assustadora. Estamos com dificuldades de elaborar tudo isso. Dessa maneira, vamos fazendo o que se torna possível ser feito...

Também mapeamos os Grupos de Pesquisa em EA do Nordeste. Para tanto, utilizamos a investigação por meio do Diretório de Pesquisa do CNPq (http://lattes.cnpq.br/web/dgp), usando a palavra chave "Educação Ambiental".

Em continuidade ao processo dessa investigação 'dialógica', ao nos aproximarmos dos resultados da pesquisa, optamos por buscar subsídios também em artigo que tratava de Abordagens teórico metodológicas em práticas de pesquisa em educação ambiental, 
apresentado durante o XXII Encontro de Pesquisa Educacional Norte e Nordeste ${ }^{3}$, em 2014, na cidade de Natal - RN (MATOS; FIGUEIREDO, 2015).

Chegamos ao cais para embarcar nessa nau que vai nos levar para a viagem até Ítaca, a célebre ilha grega, destino final da viagem de Ulisses, em sua Odisseia. Em nosso caso, esse destino simboliza uma leitura acerca das produções acadêmicas nordestinas em torno da educação ambiental. Ao manter essa metáfora da viagem, chegamos, embarcamos e transitamos ao redor de vários portos e mercados que se alargam diante de nossas leituras.

Para favorecer esse trajeto, relembramos nossas escolhas teóricas como mapas que nos sinalizam por onde ir, tal como a metodologia implica em como chegar e precisa ser orientada por teorias que nos guiem. Optamos por uma 'abordagem' dialógica de educação ambiental (FIGUEIREDO, 2007), isso significa ir a bordo, tomar lugar no barco, nos abeirarmos do que pretendemos. E, para tanto, selecionamos meios de articular as múltiplas leituras e podermos anunciar alguns achados e desvelamentos.

A denominada Educação Ambiental Crítica configura um amplo cenário repleto de complexidade e abrangência. O fundamental nela é a impossibilidade de posturas apolíticas, descomprometidas com as relações humanas, de falsas separações, fragmentações estas legitimadas no contexto da sociedade e ciência moderna. Ambas amplamente colonializantes, eurocêntrica-estadunidense. Destacamos, nesse conjunto de rompimentos normalizados na modernidade, a fratura entre ser humano e natureza, capital e trabalho, natureza não humana e ser humano; discurso e prática, objetividade e subjetividade, mercado e vida, teoria e prática.

Com uma referência dialógica, portanto crítica, garantimos essa dimensão paradigmática da Educação Ambiental - EA, e com ela a integralidade e a sacralidade da vida. Constatamos, ao longo dos estudos acerca do campo da EA, a predominância dessa tendência crítica na Educação Ambiental brasileira (REIGOTA, 2007), bem como a

\footnotetext{
${ }^{3}$ Destacamos o fato de que durante o XXII EPENN, ficou deliberado o desdobramento dos futuros encontros de pesquisadorxs da Região Nordeste e Norte. Ficou decidido que o Nordeste manterá a denominação histórica utilizada desde 1970, com a readequação retirando um dos "Ns" relativo a região norte. Salientamos ainda que os encontros científicos regionais passaram a fazer parte das atividades da Associação Nacional de PósGraduação e Pesquisa em Educação - ANPED. Portanto, partir de 2016, tivemos o XXIII EPEN.
} 
indissociabilidade entre as múltiplas dimensões, constitutivas da vida, sejam as naturais, humanas e sociais.

Nossa escolha de ações na práxis metodológica decaiu sobre a Bricolagem, enquanto arte de realizar a investigação. Desde a primeira vez que nos deparamos com o conceito de bricolagem, imediatamente nos afinamos com a proposta e o suporte teórico que lhe fundamentava. Havia uma profunda identificação com ela, pois que a mesma fazia muito sentido e compatibilidade com nossa abordagem de pesquisa. Esse encontro ocorreu ao nos aproximarmos dos estudos realizados pelo professor Barbosa (1998) acerca da Multirreferencialidade. Naquele contexto pudemos constatar a pujança da bricolagem, enquanto transgressão às ideias de ciência moderna colonializante e sua pertinência constitutiva e operatória com a dialogicidade.

Nos dicionários encontramos que bricolagem, palavra de origem francesa, trata da feitura manual, de improviso e aproveitando materiais diferentes, por meio de montagem ou instalação de qualquer coisa. Sua particular característica é ser realizada por pessoa que vai juntando partes e colando pedaços até que a obra esteja pronta.

Abrimos um parêntese para destacar sua utilização no campo das pesquisas educacionais. Cabe lembrar que, conforme Esteban (2010), a origem da pesquisa em educação principia na segunda metade do século XIX, naquele instante associada às investigações da psicologia experimental. E tinha um forte viés pragmático e instrumental, como toda dita ciência naqueles tempos. Salientamos, novamente, que nossa pretensão se funda numa proposição de superar essa lógica, em direção à decolonialidade no modo de pesquisar.

A bricolagem científica ou epistemológica pode ser reconhecida como uma maneira decolonializante e dialogal de fazer pesquisa, ao romper com essa ideia de ciência enquanto campo dogmático e restrito à círculos seletos de pessoas. Ela nos ajuda como um caminho alternativo, pautado numa concepção multirreferencial de pesquisa educacional (BORBA, 1998; BARBOSA, 1998). Nessa conjuntura de pesquisa bricolante, encontramos um grupo de intelectuais transgressores que nos favorecem com sua larga experiência e renome para podermos nos assegurar da validade desse caminhar. Destacamos nomes como Macedo 
(1998); Ardoino (1998), idealizador da Multirreferencialidade aplicada a educação, dentre tantos. Salientamos que Kincheloe e McLaren (2006) contribuem com uma fundamentação crítica para esses estudos acerca da bricolagem. Segundo Kincheloe (2007) já se evidencia a utilização da bricolagem em texto de Claude Lévi-Straus (RODRIGUES et all., 2016).

Neira e Lippi (2012), ao estudar a aplicação da bricolagem no campo da educação, resgatam que a mesma foi tratada, nas ciências sociais, primeiramente por Lévi-Strauss; por sua vez, ao aproveitar essa deixa, Derrida ressignifica o termo em aplicação na literatura, ao tratar da colagem de textos distintos numa dada obra. Segundo Neira e Lippi (2012), Certeau utilizou a bricolagem para representar a união de vários elementos culturais, gerando algo novo nesse entrecruzamento. Já no campo da pesquisa educacional, Kincheloe (2006) segue esse raciocínio e define a bricolagem como uma investigação que procura incorporar diferentes leituras acerca de um mesmo fenômeno, potencializando o enriquecimento de horizontes de percepção. Em nosso caso, agrega elementos para o diálogo na pesquisa.

Nesse procedimento de investigação, optamos pela bricolagem para entretecer, literal e figurativamente esse texto e dialogar com as informações identificadas, por meio da multiplicidade de vozes, de dimensões, de campos situacionais, de períodos históricos, com vistas ao alinhavo desse tecido aqui costurado. Compreendemos a diversidade de locais, de discursos e grupos. Dessa tessitura de diferente-iguais, a bricolagem supera a arrogância de uma única interpretação e abre o leque de possibilidades interpretativas diante do leitor/ouvinte.

Nessa feitura, acolhemos a dimensão objetiva, mas também a trans-subjetividade, numa interpretação baseada em nossa escolha crítica e dialógica. Nosso agir interpretativo acontece por meio das relações entre indivíduos, questões emergentes, representações etc. Nesse fazer bricolante, as interpretações foram tecidas, costuradas. Evidentemente, como a própria bricolagem propõe, essa é uma possibilidade de tessitura diante de outras possíveis. Os resultados serão limitados pelos aspectos apontados anteriormente, mas também pelas próprias interpretações e costuras. Contamos também nesse experimento com importante apoio da Análise Textual Discursiva de Morais e Galiazzi (2006), da Tempestade de Luz (MORAIS, 2003), para interpretar/dialogar com os resultados, sem fechar possibilidades. 
Nessa bricolagem, ou seria mais pertinente falar em brincolagem? Brincar de colagem com essas informações reconhecidas e lidas por nós? Outrxs brincantes nos antecederam com estudos nos quais definiram categorias e mostraram trajetórias anteriores. Anunciamos aqui parceirxs pesquisadorxs no campo da Educação Ambiental - EA que trouxeram importantes contributos com mapeamentos relacionados à nossa área de pesquisa, bem como a data de suas publicações e titulo dos trabalhos: Noal, F. O., Reigota, M., Barcelos, Valdo H. L. (1998): Tendências da educação ambiental brasileira; Novicki, Victor (2003): Abordagens teórico-metodológicas na pesquisa discente em educação ambiental: programas de pós-graduação em Educação do Rio de Janeiro (1981-2002); Ramos, Marcelo V.; Guerra, Antonio F. S.; Gazzoni, Castello (2005): Análise de trabalhos de educação ambiental da ANPEd; Freitas, Denise; Oliveira, Haydée T. (2006): Pesquisa em Educação Ambiental: um panorama de suas tendências metodológicas; Kawasaki, Clarice S.; Matos, Mauricio dos S.; Motokane, Marcelo T (2006): O perfil inicial do pesquisador em educação ambiental; Reigota, Marcos (2007): O Estado da Arte da Pesquisa em Educação Ambiental no Brasil; Guerra, Antonio F. S. (2008): Um panorama da inserção da educação ambiental na Região Sul; Kawasaki, C. S.; Carvalho, L. M. de. (2009a): Tendências da Pesquisa em Educação Ambiental; Kawasaki, C. S. e outros (2009b): A Pesquisa em Educação Ambiental nos ENPECs: contextos educacionais e focos temáticos.

Bem, depois dessa costura, vamos aos resultados de nossa investigação. No Nordeste Brasileiro, constatamos a existência dos seguintes grupos de pesquisa cadastrados junto ao diretório do CNPq, até 2018:

1. Coletivo Terres - Terra, Educação e Saberes - Instituição: IFRN. Líder(es): Monalisa Porto Araújo; Louize Gabriela Silva de Souza.

2. Cotidiano, Cidadania e Educação - Instituição: UEPB. Líder(es): Waldeci Ferreira Chagas; Maria Lindaci Gomes de Souza.

3. Ecopedagogia e Arteterapia: Educação, Saúde e Qualidade de Vida. Instituição: UFRN. Líder(es): Nísia Floresta Brasileira Augusta de Paula e Sousa; Maria do Socorro de Oliveira Evangelista. 
4. Educação Ambiental e Ensino de Ciências. Instituição: UFPB. Líder(es): Francisco José Pegado Abílio.

5. Grupo de Estudo e Pesquisa em educação Ambiental de Sergipe. Instituição: UFS. Líder(es): Maria Inêz Oliveira Araujo. Aline Lima de Oliveira Nepomuceno.

6. Grupo de Estudo e Pesquisa em Educação e Sustentabilidade. Instituição: UFRPE. Líder(es): Carmen Roselaine de Oliveira Farias; Renata Priscila da Silva.

7. Grupo de Estudos e Pesquisa em Educação Ambiental e Sociedades Sustentáveis - GEPEAS. Instituição: UESB. Líder(es): Cláudia Coelho Santos.

8. Grupo de Estudos e Pesquisas em Educação Ambiental Dialógica, Perspectiva Eco-Relacional e Educação Popular Freireana - GEAD. Instituição: UFC. Líder(es): João Batista de Albuquerque Figueiredo; Maria Eleni Henrique da Silva.

9. Grupo de Estudos em Educação Ambiental, Docência e Questões Contemporâneas. Instituição: UFRPE. Líder(es): Gilvaneide Ferreira de Oliveira; Angela Maria Oliveira Santa-Clara.

10. Grupo de Pesquisa e Estudo em Movimentos Sociais Educação Ambiental e Jovens e Adultos. Instituição: UVA-CE. Líder(es):Maria Neuma Clemente Galvão; Rejane Maria Gomes da Silva.

11. Grupo de Pesquisa e Estudos em Educação Ambiental, Científica e Matemática. Instituição: IFRN. Líder(es): Marcelo Aguiar Tavora.

12. Grupo de Pesquisa-Intervenção em Gestão e Educação Ambiental. Instituição: UFPI. Líder(es): Sandra Regina Lestinge.

13. Grupo Interdisciplinar de Representações Sociais e Formação em Educação e Meio Ambiente - GIRSFEMA. Instituição: UPE. Líder(es): Vera Lúcia Chalegre de Freitas.

14. Meio Ambiente. Instituição: IFPE. Líder(es): Cristiane Tessmann.

15. IEMAS - Núcleo Interdisciplinar de Estudos em Meio Ambiente e Sociedade do IFRN. Instituição: IFRN. Líder(es): Alexandre Medeiros de Araújo; José Gllauco Smith Avelino de Lima.

16. RIZOMA. Instituição: UEFS. Líder(es): Marco Antonio Leandro Barzano; Antonio Almeida da Silva. 
Contatamos, por meio dessa pesquisa, a publicação de 55 dissertações Mestrado e 22 teses de doutorado. Somando, portanto, 77 trabalhos em Educação Ambiental no Nordeste, no período de 1997 até 2018. Estas foram distribuídas nos Programas de Pós-Graduação em Educação - PPGEs da seguinte forma: Programa de Pós-Graduação em Educação da Universidade Federal do Maranhão - PPGE/UFMA - 1 Dissertação; Programa de PósGraduação em Educação da Universidade Federal do Piauí - PPGED/UFPI - 5 dissertações; Programa de Pós-Graduação em Educação Brasileira da Universidade Federal do Ceará PPGE/UFC - 11 dissertações e 11 teses; Programa de Pós-Graduação, Mestrado em Educação da Universidade Estadual do Rio Grande do Norte - POSEDUC/UERN 1 dissertação; Programa de Mestrado Profissional em Educação, Currículo, Linguagem e Inovações Pedagógicas da Universidade Federal da Bahia - MPED/UFBA - 2 dissertações; Programa de Pós-Graduação em Educação de Jovens e Adultos da Universidade Estadual da Bahia MPEJA/UNEB - 2 dissertações; Programa de Pós-Graduação em Educação e Contemporaneidade da Universidade Estadual da Bahia - PPGEDUC/UNEB - 16 dissertações e 2 teses; Programa de Pós-Graduação em Educação da Universidade Federal de Sergipe PPGED/UFS - 8 dissertações e 2 teses; Programa de Pós-Graduação em Educação Brasileira da Universidade Federal de Alagoas - PPGE/UFAL - 1 dissertação ; Programa de PósGraduação em Educação Matemática e Tecnológica da Universidade Federal Rural de Pernambuco - PPGTEG/UFRPE - 1 dissertação; Programa de Pós-Graduação em Educação da Universidade Federal de Pernambuco - PPGEdu/UFPE - 1 dissertação e 2 teses; Programa de Pós-Graduação em Educação da Universidade Federal da paraíba - PPGE/UFPB - 4 dissertações e 5 teses; Programa de Pós-Graduação em Educação Profissional do Instituto Federal do Rio Grande do Norte - PPGEP/IFRN - 1 dissertação.

Verificamos que o primeiro trabalho defendido no Nordeste, na área da educação, em que se autointitula ser de Educação Ambiental, é datado de 28.08.1997. Na verdade, foi uma dissertação de mestrado, intitulada: "Contribuição da química analítica à educação ambiental", de autoria de TORRES, Tecla Dias; orientada pelo Prof. Dr. Luiz Botelho Albuquerque no Programa de Pós-Graduação da Universidade Federal do Piauí. 
Outro dado interessante é o destaque associado ao número de orientações realizadas por pesquisadorxs nordestinxs: Avelar Luiz Bastos Mutim: 6; Francisco José Pegado Abílio: 4; João Batista de Albuquerque Figueiredo: 13; Kelma Socorro Lopes de Matos: 5; Maria Inez Oliveira Araujo: 9.

Nenhum dos PPGEs Nordestinos traz em suas linhas de pesquisa explicitamente a vinculação com Educação Ambiental. Porém, no caso do PPGE da UFC temos a referência explicita dessa temática no contexto da Linha de Pesquisa Movimentos Sociais, Educação Popular e Escola (MOSEP). Por sua vez, no Programa de Pós-Graduação em Educação e Contemporaneidade - PPGEDUC/UNEB temos a Linha de pesquisa (LPq) 3 - Educação, Gestão e Desenvolvimento Local Sustentável, que tangencia com o tema associado ao Desenvolvimento Sustentável. No Programa de Mestrado Profissional em Educação, Currículo, Linguagem e Inovações Pedagógicas - MPED/UFBA, sua Linha de pesquisa: Educação e linguagens - tem como um de seus temas o Meio Ambiente. Já o Programa de Mestrado Profissional em Educação - MPEDU/URCA apresenta, em sua Linha de pesquisa: Praticas educativas, culturas e diversidades, como um de seus temas as questões ambientais.

Quanto ao campo de atuação dessas pesquisas, reconhecemos que a educação formal associada à 'Universidade' foi o lócus privilegiado, com 22 produções $-28,6 \%$ do total, ainda que envolvam estudos distintivos sobre teorias e/ou práticas. Em virtude desse fato, cremos que o que traz mais evidencia à força das pesquisas associadas à educação ambiental formal, se apresenta como pesquisa na 'Escola' (Educação Formal), com 20 produtos - 26\%. Depois aparecem as 'Escolas afro-indígenas', com 06 trabalhos - 7,8\%; 'Escolas em assentamentos', 5 trabalhos - 6,5\%; 'Escolas do campo (sertão)', com 4 trabalhos - 5,2\%; 1 trabalho com 'EAd' - 1,3\%. Constamos 19 trabalhos executados no 'Contexto não formal da educação' (fora da escola: caçadores, grupo de mulheres, ambientes internos, praias e lagoas, rádio e tv) - 24,7\%.

Em estudo feito por Reigota (2007), encontramos similaridades quanto à informação da predominância de estudos nas dissertações identificados com a educação formal, em particular na escola pública. Carvalho e Schmidt (2008), por sua vez, afirmam que, ao 
considerar as temáticas agregadas, em estudos acerca de temáticas ambientais associadas a EA, no contexto dos três mais importantes eventos de pesquisa em Educação Ambiental, a EA na educação formal é mais expressiva que as temáticas que se ocupam da EA em espaços não formais de educação.

Em se tratando dos referenciais metodológicos, encontramos que a não explicitação desse referencial nos resumos é significativo, caracterizando $33,8 \%$ das situações, no total de 26 trabalhos acadêmicos. Naqueles trabalhos em que se explicita esse dado, constatamos que a opção mais frequente é a de Estudo de Caso, com o percentual de 14,3\%, de um total de 11 trabalhos; depois vem a Pesquisa Intervenção com 13\%, num total de 10 trabalhos; seguida de abordagens etnometodológicas com 10,4\%, num total de 08 trabalhos. Ainda a Pesquisa Ação, a teoria das Representações Sociais, Pesquisa Bibliográfica, cada uma com 6,5\%, em um número de 05 trabalhos. Em seguida, aparecem sem impacto estatístico a Sociopoética, a História Oral e a Pesquisa Colaborativa.

Percebemos nesse estudo resultados similares aos identificados por Reigota (2007). Constatamos opções teórico-metodológicas mais identificadas com a análise de percepções, signos, significados, representações... Em outras palavras, podemos pressupor um predomínio nas correntes fenomenológicas, cognitivistas, compreensivistas. Há ainda uma tendência, entre os trabalhos que enfatizam a opção metodológica, pelos estudos de caso, também similar ao constatado por Reigota (2007).

No que se refere aos aportes teóricos, a maioria esmagadora deixa de registrar nos resumos informações sobre este importante elemento, com um número de 61 dos trabalhos, caracterizando 79,2\%. Apenas 16 resumos apresentam alguma referência teórica, o que significa 16\%. Desse conjunto, 9 deles citam Paulo Freire como principal referência. Em seguida aparecem pontualmente outrxs autorxs.

Ao interagir com esse resultado, observamos aproximações com o que Carvalho e Schmidt (2008) denominam de aparente desinteresse dxs pesquisadorxs por explicitar os aspectos teóricos e metodológicos nos trabalhos apresentados. Formulamos a seguinte indagação: É uma espécie de acomodação ou seria uma fragilidade epistemológica desses pesquisadorxs? Será que temos aqui um desconhecimento da importância de escolhas 
conscientes ou apenas deixa-se de registrar por economia de palavras ou de ideias? Será que temos consciência do que significa uma teoria e uma metodologia no processo de pesquisa? Afinal, elas funcionam como mapa e arcabouço de viagem... Significam nossa própria formação, no ato de pesquisar.

No trato das palavras-chave, optamos por verificar a escolha prioritária, a secundária e a terciária como indicador que pudesse apontar a relevância que x pesquisador(a) dá as temáticas associadas à sua pesquisa. Nesse bricolar, constatamos que 'Educação Ambiental' é o tema mais destacado com 19 ocorrências, num percentual de $24,7 \%$. Como segunda palavra-chave, aparece 'Educação Ambiental' com um número de 8 ocorrências, 10,4\%. Como terceira palavra-chave o que mais aparece é 'Formação de Professores', em 3 resumos, caracterizando $3,9 \%$. Na soma dessas três palavras-chave observamos que a educação ambiental surge com força demarcando essas pesquisas, com uma soma total de 27 ocorrências, seguida da Formação de Professores aparecendo 05 vezes.

Podemos entender que as pesquisas em EA ainda se encontram bastante associadas ao campo da educação formal, porém de modo compreensivista. Dos 77 trabalhos elaborados, apenas 10 se inscrevem como Pesquisa Intervenção, apenas 13\% se apresentam explicitamente numa tentativa de mudar algo concretamente. Revisito Guimarães (2000, 2004), Barcelos (2008), Loureiro (2004a, 2004b), quando nos alertam para o compromisso histórico, ideológico e real, da EA de contribuir concretamente para a formação de pessoas críticas e criadoras de suas histórias. Isto pressupõe impactar escolhas, inclusive epistemológicas, que, num paradigma ambiental seriam também concomitantemente ontológicas.

Em nossas (In)Conclusões, nas conclusões transitórias desse estudo, do tipo "estado da arte", abrangemos produções acadêmicas desde as primeiras publicações, que aparecem nas páginas dos PPGEs do Nordeste, até os dias atuais. A primeira publicação acadêmica em educação, que versa acerca de EA explicitamente, aparece como datada de 1987. Esse acervo denota e identifica, ainda que parcialmente, a consolidação e irradiação da pesquisa em EA nas pós-graduações nordestinas em educação. Foi um estudo exploratório proporcionando saber, principalmente, o que temos produzido, onde, como e "quais 
temáticas" mais tangenciam a EA Nordestina no campo da educação. Nos oferece um caráter descritivo e preliminar, sem maiores aprofundamentos, mas com algumas inferências e diálogos geradores de novas viagens.

Realizamos esse estudo, dialogicamente, a partir da análise de resumos de dissertações e teses, mapeamentos de grupos de pesquisa, orientadorxs, temáticas, referenciais, metodologias, mas o fizemos dentro dos limites do possível, no cenário de resumos, por isso mesmo, é considerada uma etapa inicial, provocativa para realização de análises e diálogos mais aprofundados dos trabalhos na íntegra.

Nessa experiência dialógica que persevera, nesse ensaio de (in)conclusão, retomamos um diálogo acerca das três grandes vertentes epistemológicas, tratado em estudo anterior (MATOS; FIGUEIREDO, 2015), no qual ressaltamos que, ainda hoje, predominam na ambiência das ciências sociais e humanas: o Positivismo, a Fenomenologia e os Estudos Etnometodológicos, bem como a Dialética, intensamente ligada ao Materialismo Histórico. Evidentemente que em tempos mais recentes encontramos ainda as chamadas Epistemologias Emergentes, que também se identificam com ideologias contrahegemônicas, tal como a que aqui acolhemos (MINAYO,1996; MATOS e VIEIRA, 2002).

As teorias dialéticas e emergentes, regra geral, se identificam e ressoam nas propostas educativas de cunho mais crítico, tais como as que se pautam numa Pedagogia Libertadora, Libertária, Crítico-social dos Conteúdos, Cultural, Histórico-Crítica, Dialógica.

E, embora a Hermenêutica tenha sido uma brilhante tentativa de superação do positivismo ela se restringe, em geral, à tentativas de interpretação da realidade aparente. $\mathrm{E}$ isso nos mobiliza a enfatizar a relevância de um projeto educativo, no campo da educação ambiental, que possa reconhecer a essencialidade da Teoria Crítica e tudo o que ela representa de superação do aparente.

A abordagem que se diz crítica tem sido a opção mais escolhida no campo de pesquisa em EA, entretanto ainda constatamos uma forte influência das propostas compreensivistas weberianas manifestas nas pesquisas. Assim, meio que numa espécie de convocação à resistência em tempos sombrios, reconhecemos a potência paradigmática da Educação Ambiental no movimento de, criticamente como diria Paulo Freire (1983), desvelar 
a razão de ser que se encontra por trás das aparências e assim fomentar uma educação efetivamente política - própria desse Paulo Freire que ainda aparece como a principal referência práxica para as pesquisas e estudos em Educação Ambiental. Com esse aporte podemos embarcar na nau com os anteparos que poderão nos ofertar os remos, o leme, o timão, o rumo certo, para efetivar as transformações essenciais e necessárias para superar os processos opressores, a colonialidade, instigando e viabilizando a libertação.

Ainda que a fenomenologia nos ajude no desvelar do mundo, precisamos ir para além da denúncia em direção do anúncio, na feitura de um novo mundo, solidário, parceiro. Há uma luta de classe explicitada no momento atual da sociedade brasileira, essa história reapresenta e, em certa medida, reacende as contradições habituais senhor(a)-escravx, opressor(a)-oprimidxs, colonialidade-(de)colonialidade, opressão-libertação, capitalismosumak kawsay.

Existem brechas, linhas de fuga, que nos convidam para essa sociedade do compartilhamento, tal como nossos ancestrais nos propunham. Eles nos incitam a recordar que somos fazedorxs de nosso destino, da nossa história. Podemos tecer redes, teias de diálogo, de transformação social. Lembramos que Bricolagem é similar ao fuxico, artesania sertaneja nordestina que costura, em parcerias e grupos, uma nova colcha de retalhos.

Novas epistemologias geram novas propostas, novas metodologias. Podemos optar por singrar outros mares em busca de Ítaca. Podemos reconhecer os limites atuais de procedimentos de pesquisa que se limitam a identificação e visualização de problemas, para optar por alternativas que nos impulsionem à práxis transformadora.

Nos encontros, nas ações transgressoras reconhecemos o potencial de um mundo solidário. Nas relações de parceria e cooperação percebemos sementes potentes de atoslimites, enquanto ação superadora de situações-limites, restritivas. E, ainda que, inicialmente no âmbito da linguagem, podemos encontrar na dialogicidade freireana alicerces bem firmes e consistentes para avançar e tecer esse mundo-teia-rede de interações, de cooperação, no qual se torna possível amar e compartilhar o bem-viver.

\section{Referências}


BARCELOS. Valdo. Educação Ambiental: sobre princípios, metodologias e atitudes. Petrópolis, RJ: Vozes, 2008.

CARVALHO, Isabel Cristina de Moura; SCHMIDT, Leticia Santos. A pesquisa em educação ambiental: uma análise dos trabalhos apresentados na ANPED, ANPPAS e EPEA de 2001 a 2006. Revista Pesquisa em Educação Ambiental. V.3, N. 2. julho/dezembro de 2008.

CORONIL, Fernando. Natureza do pós-colonialismo: do eurocentrismo ao globocentrismo. In: LANDER, Edgardo (Org.). A colonialidade do saber: eurocentrismo e ciências sociais. 1a. ed. Buenos Aires,: Consejo Latinoamericano de Ciências Sociales - CLACSO, 2005.

FIGUEIREDO, João Batista de Albuquerque. Educação Ambiental Dialógica: as contribuições de Paulo Freire e a Cultura Sertaneja Nordestina. Fortaleza - CE: UFC, 2007.

FIGUEIREDO, J. B. A. Colonialidade e descolonialidade: uma perspectiva eco-relacional. Entrelugares: Revista de Sociopoética e Abordagens Afins., v.2, p.1 - 25, 2010.

FLEURI, Reinaldo Matias. (org.) Intercultura e Movimentos Sociais. Florianópolis, SC: MOVER/NUP, 1998.

FREIRE, Paulo. Educação como prática de liberdade. Rio de Janeiro, RJ: Paz e Terra, 1967/ 24 ed. 2000.

FREIRE, Paulo. Pedagogia do oprimido. Rio de Janeiro, RJ: Paz e Terra, 1974/13 ed., 1983.

FREIRE, Paulo. Extensão ou Comunicação? Trad. Rosisca D. de Oliveira. 10 ed. Rio de Janeiro, RJ: Paz e Terra, 1992.

FREIRE, Paulo. Pedagogia da Autonomia: Saberes necessários à prática educativa. São Paulo, SP: Paz e Terra, 1996. (Coleção Leitura).

FREIRE, Paulo. Educação e atualidade brasileira. São Paulo, SP: Cortez: Instituto Paul Freire, 2001.

FREITAS, Denise; OLIVEIRA, Haydée Torres. Pesquisa em Educação Ambiental: um panorama de suas tendências metodológicas. In: Pesquisa em Educação Ambiental, São Carlos, v. 1, n. 1, p. 175-191, jul./dez. 2006.

GUERRA, Antonio Fernando Silveira. Um panorama da inserção da educação ambiental na Região Sul. Rev. eletrônica Mestr. Educ. Ambient., Rio Grande, v. especial, p. 28-45, dez. 2008. Disponível em: <http://www.remea.furg.br/edicoes/ volesp08/art3vesp.pdf>. Acesso em: 13 fev. 2010. 
GUIMARÃES, Mauro. Educação Ambiental: no consenso um embate? Campinas: Papirus, 2000

GUIMARÃES, Mauro. Educação Ambiental Crítica. In: MMA. Identidades da Educação Ambiental Brasileira. Brasília: Ministério do Meio Ambiente. 2004.

KAWASAKI, Clarice Sumi; MATOS, Mauricio dos Santos; MOTOKANE, Marcelo Tadeu. O perfil inicial do pesquisador em educação ambiental: elementos para o estudo sobre a constituição de um campo de pesquisa em EA. Pesquisa em Educação Ambiental, São Carlos, v. 1, n. 1, p. 111-140, jul./dez. 2006.

KAWASAKI, Clarice Sumi; CARVALHO, Luiz Marcelo de. Tendências da Pesquisa em Educação Ambiental. In: Educação em Revista, v. 25, n. 3, p. 143-157, dez. 2009a.

KAWASAKI, Clarice Sumi; KATO, Danilo Seithi; VALDANHA NETO, Diógenes; SOUZA, Juliana Cristina Barbosa de; OLIVEIRA, Leonardo Basso de; MATOS, Mauricio dos Santos. A Pesquisa em Educação Ambiental nos ENPECs: contextos educacionais e focos temáticos. In: Anais do VII Encontro Nacional de Pesquisadores em Educação em Ciências, 2009. Florianópolis: UFSC, 2009b.

LANDER, Edgardo. Ciências sociais: saberes coloniais e eurocêntricos. In: LANDER, Edgardo. (Org.). A colonialidade do saber: eurocentrismo e ciências sociais. 1ạ. ed. Buenos Aires,: Consejo Latinoamericano de Ciências Sociales - CLACSO, 2005.

LOUREIRO, Carlos Frederico Bernardo. Trajetórias e Fundamentos da Educação Ambiental. São Paulo: Cortez, 2004a.

LOUREIRO, Carlos Frederico Bernardo. Educação Ambiental Transformadora. In: MMA. Identidades da Educação Ambiental Brasileira. Brasília: Ministério do Meio Ambiente, 2004b.

MATOS, Kelma Socorro Lopes de; VIEIRA, Sofia Lerche. Pesquisa educacional: o prazer de conhecer. Fortaleza: Edições Demócrito Rocha/UECE, 2002.

MATOS, Kelma Socorro Lopes de; FIGUEIREDO, João Batista de Albuquerque. Abordagens teórico metodológicas em práticas de pesquisa em educação ambiental. In: Alda Maria Duarte Araújo Castro, Maria Aparecida de Queiroz, Maria das Graças Baracho. (Org.). Assimetrias e desafios na produção do conhecimento em educação: a pós graduação nas regiões Norte e Nordeste. 1aed.Rio de Janeiro: ANPED, 2015, v. 1, p. 59-70.

MATURANA, Humberto (Humberto Maturana Romesin). Emoções e linguagem na educação e na política. Trad. José Fernandes Campo. Belo Horizonte, MG: UFMG, 1998. 
MIGNOLO, Walter. A colonialidade de cabo a rabo: o hemisfério ocidental no horizonte conceitual da modernidade. In: LANDER, Edgardo. (Org.). A colonialidade do saber: eurocentrismo e ciências sociais. 1ạ. ed. Buenos Aires,: Consejo Latinoamericano de Ciências Sociales - CLACSO, 2005.

MINAYO, Maria Cecília de Souza. O desafio do conhecimento, pesquisa qualitativa em saúde. São Paulo, SP: Hucitec, 1996.

MORAES, Roque. Tempestade de luz. In: Ciência \& Educação, v. 9, n. 2, p. 191-211, 2003.

MORAES, Roque e GALIAZZI, Maria do Carmo. Análise textual discursiva: processo Reconstrutivo de múltiplas faces. In: Ciência \& Educação, v. 12, n. 1, p. 117-128, 2006.

NOAL, Fernando Oliveira; REIGOTA, Marcos, BARCELOS, Valdo Hermes de Lima. Tendências da educação ambiental brasileira. Santa Cruz do Sul, RS: EDUNISC, 1998.

NOVICKI, Victor. Abordagens teórico-metodológicas na pesquisa discente em educação ambiental: programas de pós-graduação em Educação do Rio de Janeiro (1981-2002). In: Anais da Reunião Anual da Associação Nacional de Pesquisa e Pós-Graduação da ANPEd, 2003, Poços de Caldas, MG: ANPEd, 2003. Disponível em: <http://www. anped.org.br/reunioes/26/inicio.htm>. Acesso em: 21 fev. 2010.

QUIJANO, Aníbal. Colonialidade do poder. Revista 'Perú Indígena'. vol. 13, No. 29, 1991, pp.11-20, Lima, Peru. 1991.

QUIJANO, Aníbal. Colonialidade do poder, eurocentrismo e América Latina. In: LANDER, Edgardo. (Org.). A colonialidade do saber: eurocentrismo e ciências sociais. 1a. ed. Buenos Aires,: Consejo Latinoamericano de Ciências Sociales - CLACSO, 2005.

RAMOS, Marcelo; GUERRA, Antonio Fernando Silveira; GAZZONI, Castello. Análise de trabalhos de educação ambiental da ANPEd: uma visão segmentada das categorias de pesquisa em EA. In: ENCONTRO DE PESQUISA EM EDUCAÇÃO AMBIENTAL, 3., 2005, Ribeirão Preto. Caderno de Resumos... Ribeirão Preto, Faculdade de Filosofia, Ciências e Letras de Ribeirão Preto, USP, 2005. 1 CD-ROM.

REIGOTA, Marcos. O Estado da Arte da Pesquisa em Educação Ambiental no Brasil. Revista Pesquisa em Educação Ambiental, vol. 2, n. 1 - p. 33-66, 2007.

SANTOS, Boaventura de Sousa. A gramática do tempo: para uma nova cultura política. 2. ed. São Paulo, SP: Cortez, 2008. (Coleção para um novo senso comum; v. 4). 
SANTOS, Boaventura de Sousa. Para além do pensamento abissal: das linhas globais a uma ecologia de saberes. In: SANTOS, b. s. e MENEZES, Maria Paula. Epistemologias do sul. São Paulo, SP: Cortez, 2010.

SANTOS, Boaventura de Sousa e MENESES, Maria Paula (Orgs.). Introdução. In: SANTOS, Boaventura de Sousa; MENEZES, Maria Paula. Epistemologias do sul. São Paulo, SP: Cortez, 2010b.

WALSH, Catherine. Interculturalidad, plurinacionalidad y decolonialidad: las insurgencias político-epistémicas de refundar el Estado. Revista Tabula Rasa. vol. 9: 131-152, juliodiciembre, 2008. Bogotá - Colômbia, 2008.

WALSH, Catherine. Interculturalidad, estado, sociedade: luchas (de)coloniales de nuestra época. Quito-Equador: Universidade Andina Simón Bolívar/Ediciones Abya-Yala, 2009. 